\title{
Developing a fuzzy inference system to devise proper business strategies: a study on carpet industry
}

\author{
Nasrin Hemayatkar ${ }^{1} \cdot$ Kaveh Khalili-Damghani $^{2} \cdot$ Hosein Didehkhani ${ }^{3} \cdot$ Roohalla Samiee $^{4}$
}

Received: 28 January 2018 / Accepted: 12 June 2018/Published online: 21 June 2018

(C) The Author(s) 2018

\begin{abstract}
The present article formulates the scenarios that the organization will be probably facing with, using the uncertain factors in business environment, and it also selects the most robust strategies of organization for dealing with the formulated scenarios using the fuzzy information expressed by the experts in fuzzy inference system. The present article aims to provide a method enabling the scenario programmers to employ robustness philosophy using the scenario planning potentials and fuzzy inference system at the decision-making stage of the general process of strategy formulation. The process helps the strategic managers of the organizations to determine their business future clearly and enables them to select their robust scenario in the current market that is uncertain. After the introduction of the robust strategic planning methodology and illustrating its different stages, the selected strategies of them will be compared at the end of the article by implementing the strategic planning method in a practical case. The results of the research have been examined as a case study for carpet industry.
\end{abstract}

Keywords Fuzzy inference system · Robust scenario planning $\cdot$ Strategic management $\cdot$ Success factors of organization

Kaveh Khalili-Damghani

kaveh.khalili@gmail.com; k_khalili@azad.ac.ir

Nasrin Hemayatkar

Nasrin_Hemayatkar@yahoo.com

Hosein Didehkhani

h.didehkhani@gmail.com

Roohalla Samiee

roohalla.samiee@gmail.com

1 Department of Entrepreneurship, Faculty of Management and Accounting, Aliabad Katoul Branch, Islamic Azad University, Aliabad Katoul, Golestan, Iran

2 Department of Industrial Engineering, Faculty of Industrial Engineering, South Tehran Branch, Islamic Azad University, Tehran, Iran

3 Department of Industrial Engineering, Faculty of Management and Accounting, Aliabad Katoul Branch, Islamic Azad University, Aliabad Katoul, Golestan, Iran

4 Department of Management, Faculty of Management and Accounting, Aliabad Katoul Branch, Islamic Azad University, Aliabad Katoul, Golestan, Iran

\section{Introduction}

Iran has $1.4 \%$ of the world's population while its share of world's production and exportation is $0.3 \%$. There are about 2.5 million weavers working both full time and part time in Iran, and about 5.8\% people are involved directly or indirectly in carpet industry (Karimi et al. 2016). Iran holds about $8 \%$ of the world's carpet business. The average sale of carpets in Iran was 513 million dollars in 2016. The share of Iran in international carpet market was about 55\%, but it has plummeted to less than 25\% (Light and Shahlapour 2017). The main components of Iran are: China, India, Nepal, Pakistan and Turkey. The wages and costs of producing carpets in Iran is higher than its competitors such as India, China and Pakistan because on the one hand these countries have cheap workforce in great numbers and on the other hand the rate of bank facilities granted to the carpet weavers is very low or zero (Propa et al. 2018).

Regarding the profound changes in different fields, the business environment has also been subject to a lot of instabilities and unreliability and a great competition has been created in the business environment. The organizational systems should utilize a planning that is both 
forward-looking and environmentalist to succeed in the competition in a way that while the environmental factors and changes are identified over a long time horizon, their impacts on the organization and the way the organization interacts with them will be determined. This type of planning is in fact strategic planning that identifies the internal strengths and weaknesses and environmental opportunities and threats and formulates some long-term goals for the organization considering the mission of the organization and selects one strategy from among the strategic options, making the optimum use of the opportunities and avoiding the threats by depending on the strengths and removing the weaknesses so that it will finally make the organization succeed in the competition (Bayar et al. 2018).

Strategic planning is mainly formulated based on the current realities of the market and the available information that are generally based on the past and present performance of the organization and competitors. Although, it is not possible to ignore the share of expertise, experience and qualitative prediction of the future conditions of the market. However, the question is that how effective can the qualitative and inexact analyses be that are based on personal experience without any systematic support in the disorderly and unstable markets in the presence and appearance of the competitors and their continuous growth?, or to what extent are those analyses able to understand and make a model the effect of the change in several variables and the interactions among the variables over time, and have the foresight to deal with the future conditions?! (Martinsons et al. 2017). Some of the issue is related to the complexities of the probable scenarios, variety of the indices and the existing uncertainties. Some of the error is related to the passage of continuity (Dmitrieva et al. 2017). The business environments contain a storm of changes, dynamics, conversions and transfers. The traditional methods of strategic planning devise strategies based on the certain predictions about the future. The predictions and analyses of the current conditions and the past experiences are used to outline the course of the events and their future trend. The more disorderly the environment is, the more rapid the changes are and the predictions are more likely to be unrealized. Therefore, the mentioned methods in the strategic planning lose their efficiency facing these uncertain factors and environmental changes. These have made some tools appear and become popular giving the programmers or planners the intuition and power to confront the environmental changes. Some tools such as stochastic, scenario planning, decision analysis and game theory are among the mentioned tools. Scenario planning is one of the common methods to deal with the uncertainty in the environment that enjoys an increasing popularity among the programmers because of its capabilities to depict the probable futures.

The methodology of the present article has been designed at three stages. The first stage intends to recognize the environment where the organization operates, and it determines the strategic condition of the organization with the help of the general strategic planning tools. Also, a portfolio of the possible strategies is extracted for the organization. In the second stage, the main factors involved in the uncertainty of the environment are identified and the potential scenarios for future environment of the organization are identified by combining different amounts of the factors. Finally in the third stage, each strategy the organization faces with is assessed against each scenario. In this stage, the knowledge base of each strategy is determined using the experts' opinions.

The mentioned knowledge base determines the effect of the strategy on the vital factors in organization success. The performance of each strategy is assessed by measuring the improvement made in the vital success factors. The specifications of the scenarios enter the strategic knowledge base, and the performance resulting from the implementation of the strategy is measured by making use of fuzzy inference system. Considering the performance of each strategy during different scenarios, the robust strategy is identified from among the strategies existing in the portfolio. The robust strategy is considered a strategy that maintains its efficiency and attractiveness when facing different future states that are commonly called the future scenarios. Although a robust strategy may not be the best strategy in a particular scenario, it will be the most suitable strategy considering all futures scenarios. Therefore, the robust strategy has the following feature. It is acceptable for all future scenarios and can be implemented in all of them; in other words, we cannot call a strategy that is only suitable for a particular scenario as a robust one.

The present article aims to provide a method by employing the capabilities of scenario planning and fuzzy inference system in order to make it possible for the programmers to use stability philosophy in the decisionmaking phase of the general process of strategy formulation. In fact, the provided methodology offers a method used to prioritize the strategies and it is considered as a substitute for strategic planning matrix. This methodology also features the capabilities of the general methods and tools at two input and comparison phases. It is possible to gain the input of the mentioned methodology by the information related to the intra-organizational and extraorganizational factors and the list of strategies that was obtained in the two previous phases.

Table 1 presents the main steps of the research. As mentioned, three steps of the research are input stage in which the internal factor evaluation matrix, competitive 
Table 1 Analytic framework to devise strategies

First stage: Input stage
IFE: Internal factor $\quad$ CPM: Competitive profile matrix $\quad$ EFE: External factor evaluation matrix

evaluation matrix

Second stage: Evaluation stage

$\begin{array}{cc}\text { The main strategy matrix } & \begin{array}{c}\text { IE: Internal/ } \\ \text { external }\end{array} \\ \text { BCG: Boston } \\ \text { consultation group }\end{array}$

SPACE: Strategic position

action evaluation
TOWS: Treats opportunities

weaknesses strengths, matrix

Third stage: Decision stage

Quantitative strategic planning matrix

profile matrix and external factor evaluation matrix are formed, the evaluation stage in which the main strategy matrix is formed and the decision stage in which the best decision is made.

The next sections of the paper are organized as follows. "Review of literature" section is allocated to review of the literature of the past works. "Research methodology" section presents the proposed methodology of this study. "Case study" section presents the case study. The results are discussed in "Result analysis" section. "Conclusion" section is allocated to present the conclusion remarks and future researches directions.

\section{Review of literature}

In this section, different types of business strategies and the methods used to confront each strategy will be discussed.

\section{Strategic planning}

Planning is categorized in terms of its nature into the following groups: physical planning, organizational planning, process planning, financial planning, duty planning and general planning. Planning in terms of the time horizon can be categorized into short term, medium term and long term (Dmitrieva et al. 2017). Most of the planning is in the form of "ideals and goals, designs and actions, and the required resources" according to the logical view (Papke-Shields and Boyer-Wright 2017). In these models, firstly the ideals and goals of the organization are explained, then the required designs and actions are determined and finally the resources required implementing the plan. As opposed to the traditional planning in which the ideals and goals are determined, the objective of the strategic planning is to explain and devise the strategy. It is possible to employ a combination of traditional planning and strategic planning depending on the type, variety and nature of the changes existing in the environment (Hu et al. 2017). The strategic planning is a type of planning whose objective is to define and devise strategies. The strategic planning is a structured attempt to make major decisions and take actions that form and lead the nature of the organization, type of activities and the reason for the activities done by the organization. Devising the strategy and preparing strategic plans, determining the general future orientations of the organization and the statements of values, missions, perspectives and also determining the fundamental objectives, and finally the networks of the medium term and operational goals as well as the strategies at different management levels of the organization are interacting with the complex environment and the uncertainty, dynamics and fluidity of the environmental conditions and factors. The step which is more important than devising the strategy is to formulate and explain the methods to execute them in a way that the perspective and fundamental goals are in line with each other and the medium-term objectives and operational targets are related and synergetic (Greiner et al. 2014). There are different methods to execute the strategies that operationalize the strategies employing the techniques experienced at a global level, and finally the performance is assessed in the same framework. The balanced scorecards method is used in many agencies and organizations, and the examination of the course of its transformation course shows that the method has been recognized all around the world as an appropriate method in employing a strategy which is currently a common method globally.

The strategic planning offers a framework for the activities of the organization and its managers and staffs to achieve the analysis of strategic situation, choice of common language and decisions that must be made at the right time, in response to these questions through which it helps the organization to achieve a comprehensive development, good organization and gain a better understanding of the environment and the current and prospective customer, and it also helps the organization to become aware of its capabilities and limitations (Norooz and Wikner 2017).

\section{Dynamic strategic management}

There are numerous definitions for dynamic strategic management in the related literature. Some of the proposed 
definitions are as follows: Goodstein, Nolan and Feiffer maintained in 1992 that: The dynamic strategic management is a process through which the members of a future organization are visualized and the process creates the procedures and actions required to achieve them (Pesonen 2009). The dynamic strategic management is a decisionmaking process which can relate the environment within the organization to the opportunities and threats coming from the outside of the organization in such a way that the value of each factor will be completely obvious (Cosenz and Noto 2018). Propa et al. (2018) examined the performance of handwoven carpet using Business Performance Evaluation Technique I (BPET I). Then, they developed this method through combining this method with balanced scorecards method and named it BPET II. The method BEPET I categorizes the important indices in selling carpets, and it is very important for the market performance; then, the criteria in question are evaluated and the solutions and sensitivity analysis are provided by executing BPET II.

\section{The methods of predicting supply and demand functions}

Chen and Tan (2017) aimed at predicting the demands in electric power industry. They employed regression and machine learning methods to predict the amount of the demands required to the industry. The case study conducted for the study is to predict the required demands for chain hotels. The results of the prediction were compared to the historical data, and the $1 \%$ error indicates the good performance of the proposed model. Brentan et al. (2017) aimed at predicting the demands for water by the distributing centers. They employed time series and regression methods to predict the demands over a short period of time. The case study conducted for this study was Brazil. One of the goals of the present research was to reduce the risks and costs of predictions. The results of the research express the acceptable performance of the proposed model, and the average $4 \%$ error is gained in comparison with the historical data. Jiménez et al. (2017) proposed an approach to predict the sales of different products. The name of the approach proposed in this study is ENORA; it is in fact a type of evolutionary algorithm that is based on non-dominated sorting. The model proposed by this study to predict the sale is multipurpose, and one of its purposes is to reduce the error and error variance. Also, this algorithm has been compared with NSGA-II method to prove the offered solution, and the results show the acceptable performance of this approach in comparison with NGSA-II. Lessmann and Voß (2017) developed a static model to predict the sales and prices of used cars. Some sensitivity analyses with different degrees of freedom have been done to the proposed model. They have used the linear regression and multivariate approach for the analyses. The results show that the periodical increase in the prediction of the estimated value is improved and the estimation error will be less. Gao et al. (2017) proposed a hybrid optimization approach to forecast automobile sales in China. Zhao and Zhu (2018) proposed a risk-averse marketing strategy and its effect on coordination activities in a remanufacturing supply chain under market fluctuation.

\section{Business development models}

Some researchers have also pointed out in greater details the value chain, main flows of production or some activities such as marketing (Burge and Luke 2017). In an economic approach, the business plan is known to be the logic of turning profits in a company. For example, we can mention the definition of business model proposed by Fjeldstad and Snow (2018) that defines the business model as the way to make money and maintain the flow of profit over time. Some different items and even some general expressions such as financial and accounting concepts have been pointed out in this viewpoint. In this section, some researchers have also pointed out the general benefits of the company, business goals and efficiency. Although these concepts include some goals beyond mere economic goals such as social goals, the goal of a nonprofit institution is to generate profits.

\section{Network business model}

Since the process of creating values in today's world is done through a network and beyond the limited boundaries of a company, the organization interacts with numerous actors in its business. One of the actors is the collection of factors involved in fulfilling the duty of creating, marketing and providing value including the partners such as the suppliers and providers. In a broader perspective, even the rivals and general organizations such as the public representatives and agencies are considered the actors. Some definitions indicate one section of the actors, and some others indicate a collection of the actors by taking a more comprehensive view. However, the organizational actors are not the only actors involved in a business and the customers are also considered the actors in a business. The expert systems are used in many fields including the business plans, security systems, exploitation of oil and mines, genetic engineering, designing and making cars, designing camera lens and airline flight schedules. Kuo et al. (2016) aimed at predicting the sales of laptops in Taiwan using fuzzy neural network. The previous predicting approaches take only the quantitative data into consideration; however, the qualitative data also affect the prediction of the sales of laptop in this approach. 
Therefore, the qualitative criteria and data are collected according to the experts' opinions; then, the prediction about the sales of products is made using back-propagation neural network. The results show that the proposed method performs better than other predicting methods, and it has been able to reduce the costs to a considerable amount. Wang et al. (2011) proposed an approach using fuzzy inference system to predict the car sales. The data used in this study are related to the sales in Taiwan in the last month. Some of the data used in predicting the sales of the cars are: past sales, wholesale prices, income and the dependent variables. In the following, the prediction has been made using ANFIS. The results of the prediction have been compared to the results obtained using ARIMA, and the result shows that both models are acceptable and they both have a low number of errors. Gao et al. (2017) used the particle swarm hybrid fuzzy approach and ant algorithm to predict the sales of the cars in China. We can mention the DGP and the distance travelled by the cars in the freeways and also the consumer price as some of the indices used by this prediction. One of the goals of the present study is to reduce the current costs and enhance the customer satisfaction. The results express the proper performance of the proposed hybrid model in predicting the car sales.

\section{Reducing the costs of a strategy}

The decisions about the reduction in costs should be based on a profound knowledge and understanding of all phases of producing a product from designing to sale (providing services) and after sales. The managers should identify the costs that create values and those not creating any values. The approach of strategic reduction in the prices and improvement in the performance has been developed relying on the principle of the relation between improvements in organization's performance with the cost reduction. The costs are often reduced by eliminating the production of wastes, and as a result, the costs are reduced. The companies that follow this strategy try to reduce the prices of their products without running at a loss (Aghazadeh 2015).

\section{Partnership strategy}

One of the famous strategies employed by the companies is to partner with others where two or more companies form a temporary partnership or consortium and make use of the opportunity. The strategy could be called a defensive cooperative strategy because no single companies undertake to implement a plan. Often two or three companies take on the corporate responsibility and start to operate as a newly established company and supply the required capital together (they form a type of general partnership); other types of cooperative are: $R \& D$ general partnership, general partnership companies distributing the goods produced by the other partners. Table 2 shows examination of review of literature and comparing the previous studies and current study.

It can be concluded from Table 2 that the present study provides a method for strategic planning in the level of organizational planning incorporating market penetration, developing the products using fuzzy inference system. The aforementioned combination is not reported in the literature of past research work and is discussed in this research.

\section{Research methodology}

In this section, the process of creating scenarios and selection of the robust strategy are expressed using fuzzy inference. The obvious feature of this method is the emphasis on simplification of the scenario designing process to increase its applicability and chance of success. The decision-making process includes two stages, as it can be observed in Fig. 1.

- Formulating the scenarios

- Determining the organization strategy

- Decision making

Determining environmental stimuli Stimuli are divided into two groups, namely "known in advance" and "unpredictable." In order to distinguish the unpredictable stimuli from the stimuli that are known in advance, the stimuli obtained from the entrance stage are rated according to two criteria of importance and uncertainty. The very crucial and certain stimuli are identified, and their possible amounts are expressed.

Designing the scenarios Scenario designing is used in order to convert the identified stimuli into a limited number of scenarios. The scenarios designing team discusses the probable future events, by holding numerous brainstorm meetings, and examines the factors creating the events and their consequences, and then the scenarios are created based on the events.

The evaluation and examination of the formulated scenarios Since it is not logical and possible to have all possible combinations of stimuli, the experts and programmers in the organization examine the initial scenarios in this stage and analyze them in terms of the compatibility of the mentioned trends with the interval. Therefore, the scenarios that are impossible to occur in practice are eliminated.

Composing the scenarios with full details At this stage, we can use graphs, tables and illustrative descriptions. The 


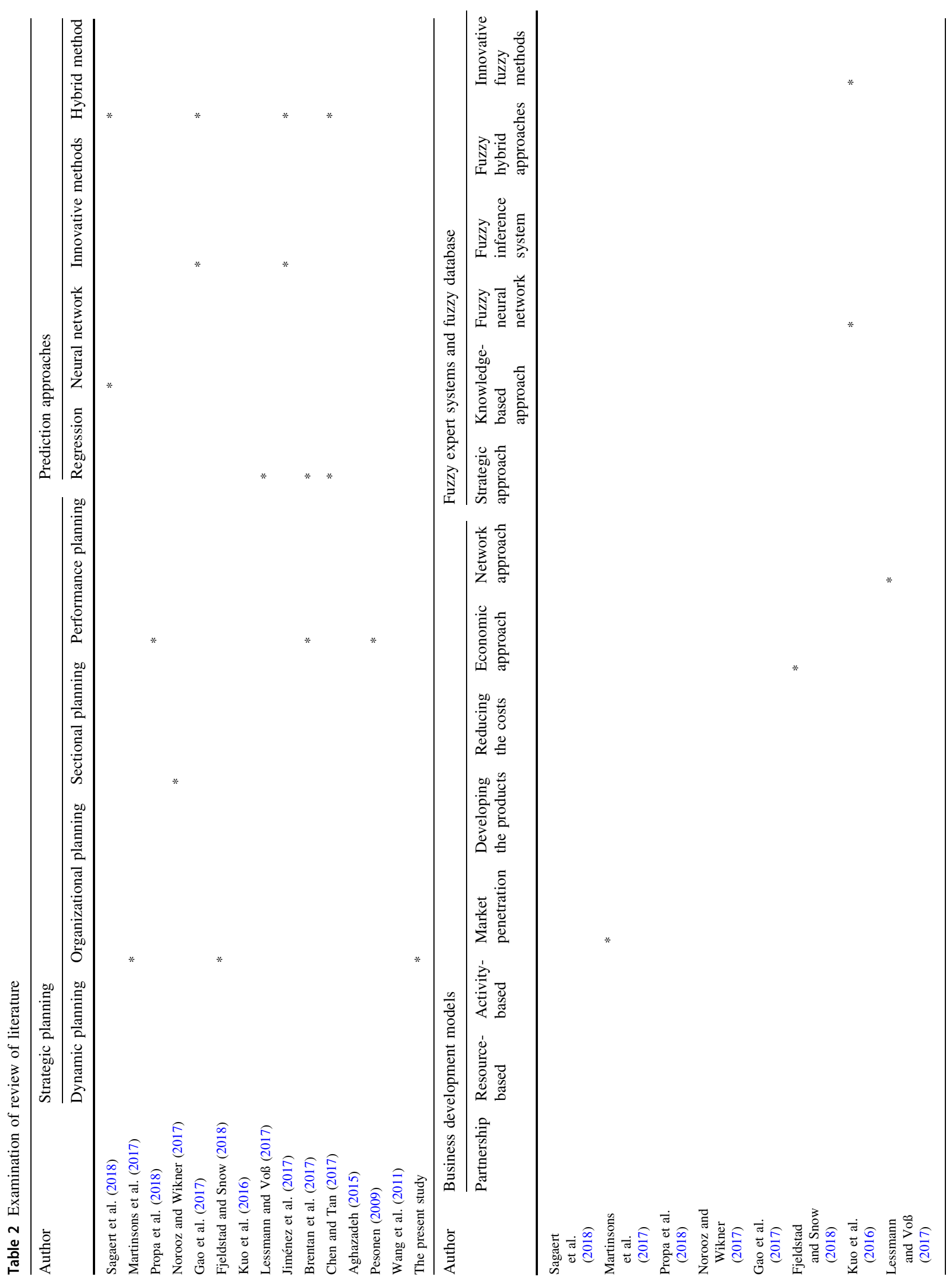




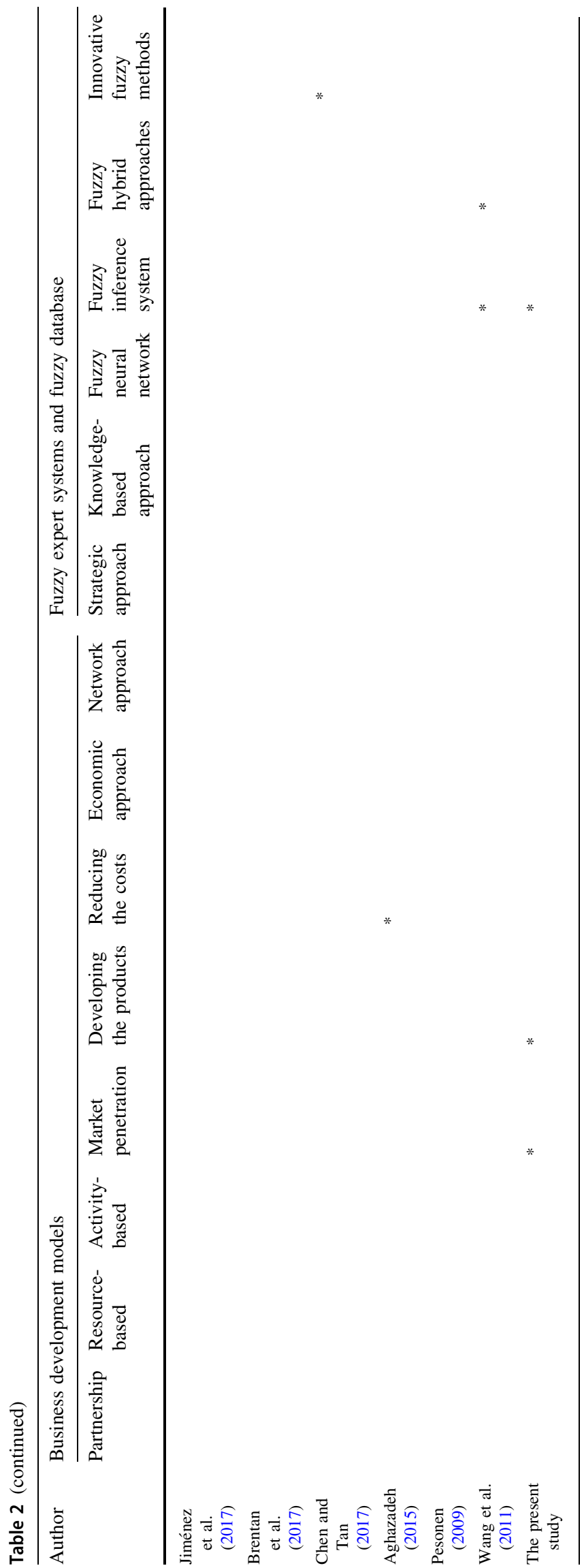

amounts of stimuli in the scenarios in whatever way they have been illustrated, finally, are translated as linguistic variables so that they will be capable to enter the fuzzy inference system that is a concept which will be explained in the next stages.

Determining the strategy The base of the mentioned rules is created by making use of the knowledge of the experts and managers in the organization and through linguistic variables. These variables usually take on one of the following membership functions: steady, triangular, trapezoidal and Gaussian. Fuzzy inference system helps the planners to be able to measure the effects of implementing the strategy on the vital success factors of the organization by making use of the rule base of each strategy by assuming that a certain scenario will occur. Considering the above explanations, it is necessary that the following four activities occur at this stage: (a) determining the organization vital success factors; (b) forming the rule base of each strategy; (c) implementing fuzzy inference system; and (d) selecting the organization robust strategy.

Determining the vital success factors of the organization There are 3-6 factors known as organization vital success factors in each business; in case the organization succeeds in realizing them, it can be sure about its success in competitive performance. In fact it is possible to make sure of the health and success of the organization by examining and assessing these factors, and we can also assess the performance of the strategies implemented in the organization by examining and assessing the mentioned factors.

Creating the rule base of each strategy Each strategy reflects some certain amounts of vital success factors for the organization when facing different amounts of stimuli. It is possible to predict the specific combinations of environmental stimuli and vital success factors resulting from implementing a certain strategy. For example, by using the experts' opinions, it is possible to predict that, for example, if the demands increase and the wages remain at the same usual amount, then for instance implementing strategy 1 increases sales; however, it does not make any changes in the workers' motivations.

Implementing fuzzy inference system The specifications of each scenario enter the strategic knowledge base in order to implement fuzzy inference system, and the fuzzy inference engine measures the output, i.e., the amounts of vital success factors using the rules existing in the base.

Selecting the robust strategy of the organization At this stage, the strategy is selected that has been dominant in most scenarios. In other words, the strategy that is only desirable and suitable in a certain scenario which is not 


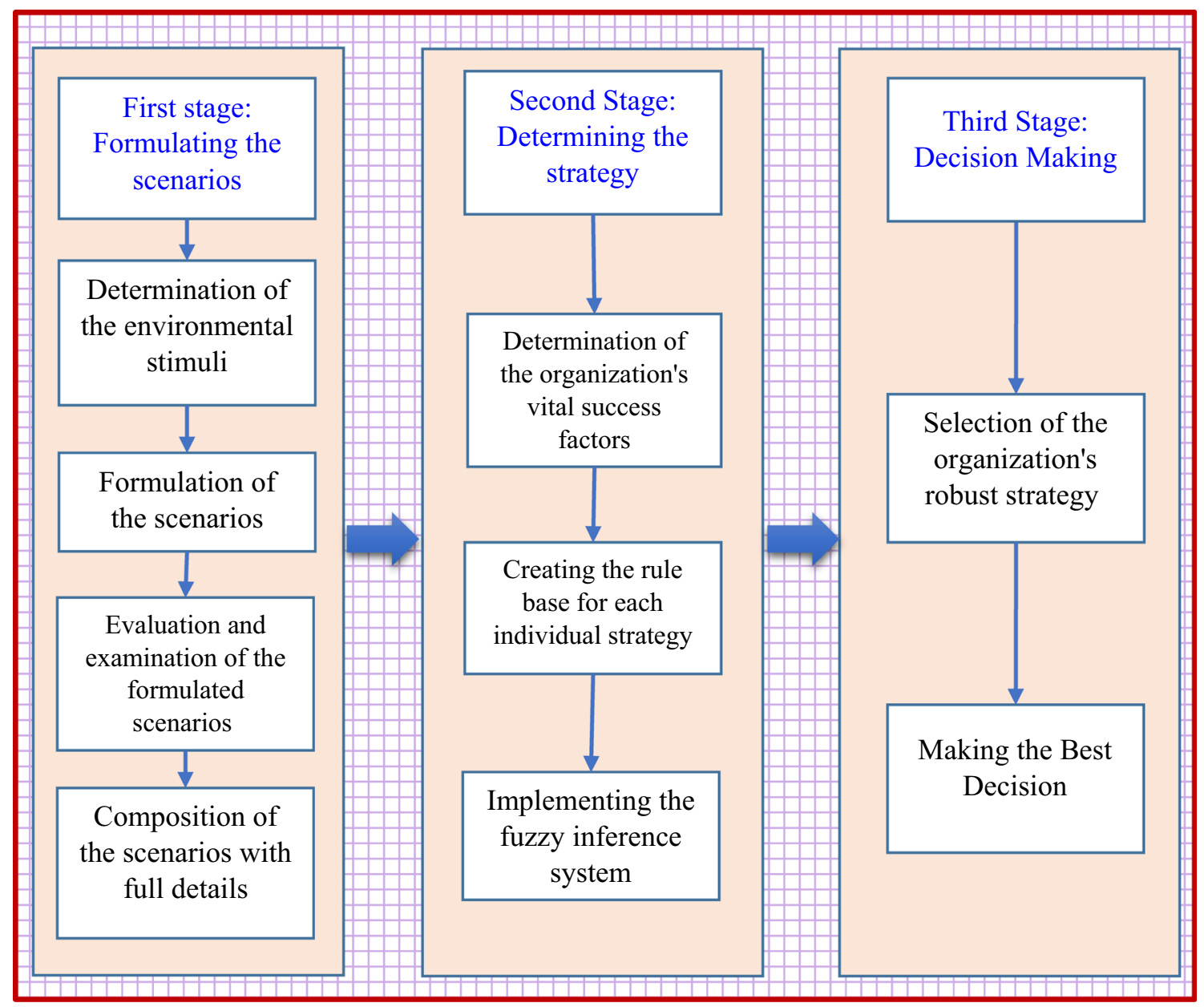

Fig. 1 Conceptual model of the research

acceptable in other scenarios cannot be called a robust scenario.

Making the best decision At this stage, the best decision is made.

\section{Fuzzy inference system}

As the main part of the proposed approach if this paper includes fuzzy inference system (FIS), the logic of a FIS is briefly reviewed here.

FIS is the process of formulating the mapping from a given input to an output using fuzzy logic. The mapping then provides a basis from which decisions can be made, or patterns discerned. The process of fuzzy inference involves all of the pieces that are described in the previous sections: membership functions, fuzzy logic operators and if-then rules. There are two types of FIS that can be implemented: Mamdani type and Sugeno type. These two types of inference systems vary somewhat in the way outputs are determined. FISs have been successfully applied in fields such as automatic control, data classification, decision analysis, expert systems and computer vision. Because of its multidisciplinary nature, FISs are associated with a number of names, such as fuzzy-rule-based systems, fuzzy expert systems, fuzzy modeling, fuzzy associative memory, fuzzy logic controllers and fuzzy systems. Since the terms used to describe the various parts of the fuzzy inference process are far from standard, we will try to be as clear as possible about the different terms introduced in this section.

Mamdani's fuzzy inference method is the most commonly seen fuzzy methodology. Mamdani's method was among the first control systems built using fuzzy set theory. It was proposed in 1975 by Ebrahim Mamdani (Mamdani and Assilian 1975) as an attempt to control a steam engine and boiler combination by synthesizing a set of linguistic control rules obtained from experienced human operators. Mamdani-type inference expects the output membership functions to be fuzzy sets. After the aggregation process, there is a fuzzy set for each output variable that needs 
Table 3 Selected strategies

\begin{tabular}{lll}
\hline Strategy & Title & Description \\
\hline$\# 1$ & $\begin{array}{l}\text { Product development and } \\
\text { services }\end{array}$ & Increasing the sales by improving the current products \\
\#2 & Market development & $\begin{array}{l}\text { Providing the current products and services for the new areas } \\
\text { \#3 }\end{array}$ \\
Partnership & $\begin{array}{l}\text { Making use of the technological advantages and brands of the companies that are famous } \\
\text { worldwide }\end{array}$ & Reduction in costs by increasing the production and return to scale \\
\hline
\end{tabular}

defuzzification. In general, Sugeno-type systems can be used to model any inference system in which the output membership functions are either linear or constant.

\section{Case study}

The Zomorrod Carpet Co. has started manufacturing machine-made carpets since 1997. The company has developed ever since because of the efforts on the part of all managers, staffs and the unsparing support of the chief executives and the board of directors in a way that it is considered now one of the largest and most reputable companies manufacturing machine-made carpet. The robust methodology was implemented in the company along with the strategic planning project that was being done using the general strategic planning; at the end, the difference between the output strategies resulting from the robust methodology proposed by this paper and the classic strategic planning project was presented to the chief executives. The executive team with 20 members consists of the representatives from all units and levels of the organization. The mentioned team formulated its strategies using David framework after preparing the mission of the organization and receiving the confirmation of the chief executives. The stages that were completed are presented in Table 3.

As it can be observed in the above table, after recognizing the internal and external factors in the first stage, the list of possible strategies is extracted using two matrices, namely the matrix of threats, opportunities, weaknesses and strengths and the strategic position and action evaluation matrix, and the strategic situation of the organization is determined. Finally, each one of the above strategic planning matrices is rated by quantitative strategic planning matrix of desirability according to their responsiveness to the environmental opportunities and threats and also the weaknesses and strengths of the organization, and as a result, the partnership strategy was selected as the proper strategy for the organization according to the general method of strategic planning.

It should be noted that the identified environmental stimuli are rated based on two criteria of the importance and the extent of uncertainty at the first stage and after preparing the external factor evaluation table. The importance coefficient shows the relative importance of a factor

Table 4 Different states of stimuli

\begin{tabular}{|c|c|}
\hline Demand & $\begin{array}{l}\text { Whether it increases or remains the same } \\
\text { Increase the current trend } \\
\text { Increase it suddenly and dramatically }\end{array}$ \\
\hline Foreign investment & $\begin{array}{l}\text { Reduction in foreign investment } \\
\text { Continuation of the current trend } \\
\text { Considerable increase in it }\end{array}$ \\
\hline $\begin{array}{l}\text { Performance of rival } \\
\text { companies }\end{array}$ & $\begin{array}{l}\text { Weak: meaning that there are no serious rivals in the market } \\
\text { Medium: The foreign rivals have not entered the market, but the domestic rivals can be threatening in some } \\
\text { sections of the market } \\
\text { Strong: The domestic rivals have penetrated in all sections of the market and they can restrict our share in the } \\
\text { market }\end{array}$ \\
\hline $\begin{array}{l}\text { Costs of the specialized } \\
\text { forces }\end{array}$ & $\begin{array}{l}\text { It increases very slowly } \\
\text { Continue the existing trend toward increasing the costs man force } \\
\text { Increase it dramatically }\end{array}$ \\
\hline
\end{tabular}


in comparison with other factors. The same coefficient exists in the calculations presented in the external factor evaluation matrix table. The second criteria express the amount of uncertainty of the given stimulus. The larger the amount of these factors is, the more difficult and riskier the determination and prediction of the future amount of the mentioned stimulus will be. The goal of this ranking is to select the stimuli that are highly important and very certain. Finally, four factors were selected from among the stimuli that are presented in Table 4.

\section{Demand}

The increasing tendency of the organizations and industries to use the potential abilities of IT in order to facilitate the activities and improve their efficiency can bring about an increase in the demands; however, some factors such as economic depression, war, imposing sanctions on technological countries and inability of the market to meet more demands and the obsolesce of the current technology and products always pose the risk that the number of demands remains the same or even decreases.

\section{Foreign investment}

Regarding the fertile market in Iran and the demands that have not been saturated in this market and also the need for massive investments and executing huge projects to build the infrastructure required by this industry, it is unavoidable to use the foreign investments.

\section{Performance of the rival companies}

IT industry is generally, and particularly in Iran, among the industries that are good options to invest in because of their strong potential, and this may create some new strong rivals or it may make the existing rivals boost themselves and their investments.

\section{The costs of specialized personnel}

The specialized personnel are considered the main resource in carpet industry. Therefore, the costs of this resource play an important role in the prime costs of the products and services.

\section{Result analysis}

The official future of the company was expressed by using the predictions and observing the current trends and annual reports of the company in order to determine the scenarios. All stages mentioned above were completed during the brainstorm meetings in the presence of the managers of all units, and the CEO of the organization was informed of the results. The mentioned scenarios are explained below:

\section{First scenario}

The predictable world: In this scenario, all factors and conditions change according to the predictions and programs of Iran's 20-year vision plan. The existing trends will continue without experiencing any change or sudden transformations. The demands will increase and the economic growth continues according to the 20 -year vision plan. The monopoly on the market will be eliminated, and foreign investments and the involvement of the foreign rivals will be possible. The government will continue support the domestic companies. There is sufficient specialized man force, and the costs of man force increase according to the inflation.

Table 5 Combinations of stimulus amounts of different scenarios

\begin{tabular}{|c|c|c|c|c|c|c|c|c|}
\hline \multirow{2}{*}{$\begin{array}{l}\text { Stimuli } \\
\text { Scenario }\end{array}$} & \multicolumn{2}{|l|}{ Demand } & \multicolumn{2}{|c|}{ Foreign investment } & \multicolumn{2}{|c|}{ Man force costs } & \multicolumn{2}{|c|}{ Rivals' performance } \\
\hline & Qualitative & Quantitative & Qualitative & Quantitative & Qualitative & Quantitative & Qualitative & Quantitative \\
\hline Predictable world & Low & 2.5 & Normal & 6.5 & Normal & 3 & Normal & 2.5 \\
\hline Nightmare & High & 8.5 & Low & 1.5 & High & 8 & High & 7.5 \\
\hline Great wishes & Normal & 5.5 & High & 9 & Normal & 7 & Low & 3 \\
\hline
\end{tabular}

Table 6 Vital success factors

\begin{tabular}{llll}
\hline & Aspect & Vital success factors & Weight \\
\hline 1 & Financial & Percentage of sales' profit & 0.26 \\
2 & Customer & Customer satisfaction index & 0.25 \\
3 & Internal processes & Percentage of standardized activities & 0.25 \\
4 & Personnel's growth and learning & Personnel's motivation index & 0.24 \\
\hline
\end{tabular}


Table 7 Strategy-factor table

\begin{tabular}{|c|c|c|c|c|c|c|c|c|}
\hline \multirow[t]{2}{*}{ Strategy } & \multicolumn{4}{|l|}{ Stimuli } & \multicolumn{4}{|c|}{ Vital success factors } \\
\hline & Demand & $\begin{array}{l}\text { Foreign } \\
\text { investment }\end{array}$ & $\begin{array}{l}\text { Costs of human } \\
\text { resource }\end{array}$ & $\begin{array}{l}\text { Rivals' } \\
\text { performance }\end{array}$ & Profit & $\begin{array}{l}\text { Customer } \\
\text { satisfaction }\end{array}$ & $\begin{array}{l}\text { Duration of meeting } \\
\text { the demand }\end{array}$ & Motivation \\
\hline \multirow{4}{*}{$\begin{array}{l}\text { Developing } \\
\text { products }\end{array}$} & High & - & Normal & & High & High & - & High \\
\hline & Low & & Low & & Low & High & & Normal \\
\hline & Normal & & Normal & & Normal & High & & Normal \\
\hline & Normal & & Normal & & High & High & & High \\
\hline \multirow{4}{*}{$\begin{array}{l}\text { Developing the } \\
\text { market }\end{array}$} & High & - & Normal & & High & - & - & High \\
\hline & Low & & Normal & & Normal & & & High \\
\hline & Normal & & High & & High & & & High \\
\hline & Normal & & Low & & High & & & High \\
\hline \multirow{4}{*}{$\begin{array}{l}\text { Reducing the } \\
\text { costs }\end{array}$} & - & High & Normal & Normal & High & High & High & - \\
\hline & & Low & Normal & Normal & High & Normal & High & \\
\hline & & Normal & High & Normal & Normal & Normal & High & \\
\hline & & Normal & Normal & High & High & High & Normal & \\
\hline \multirow[t]{4}{*}{ Partnership } & - & Normal & High & & High & Normal & High & High \\
\hline & & Normal & Low & & High & High & High & High \\
\hline & & Normal & High & & Normal & Normal & High & High \\
\hline & & Low & High & & Normal & Normal & Normal & High \\
\hline
\end{tabular}

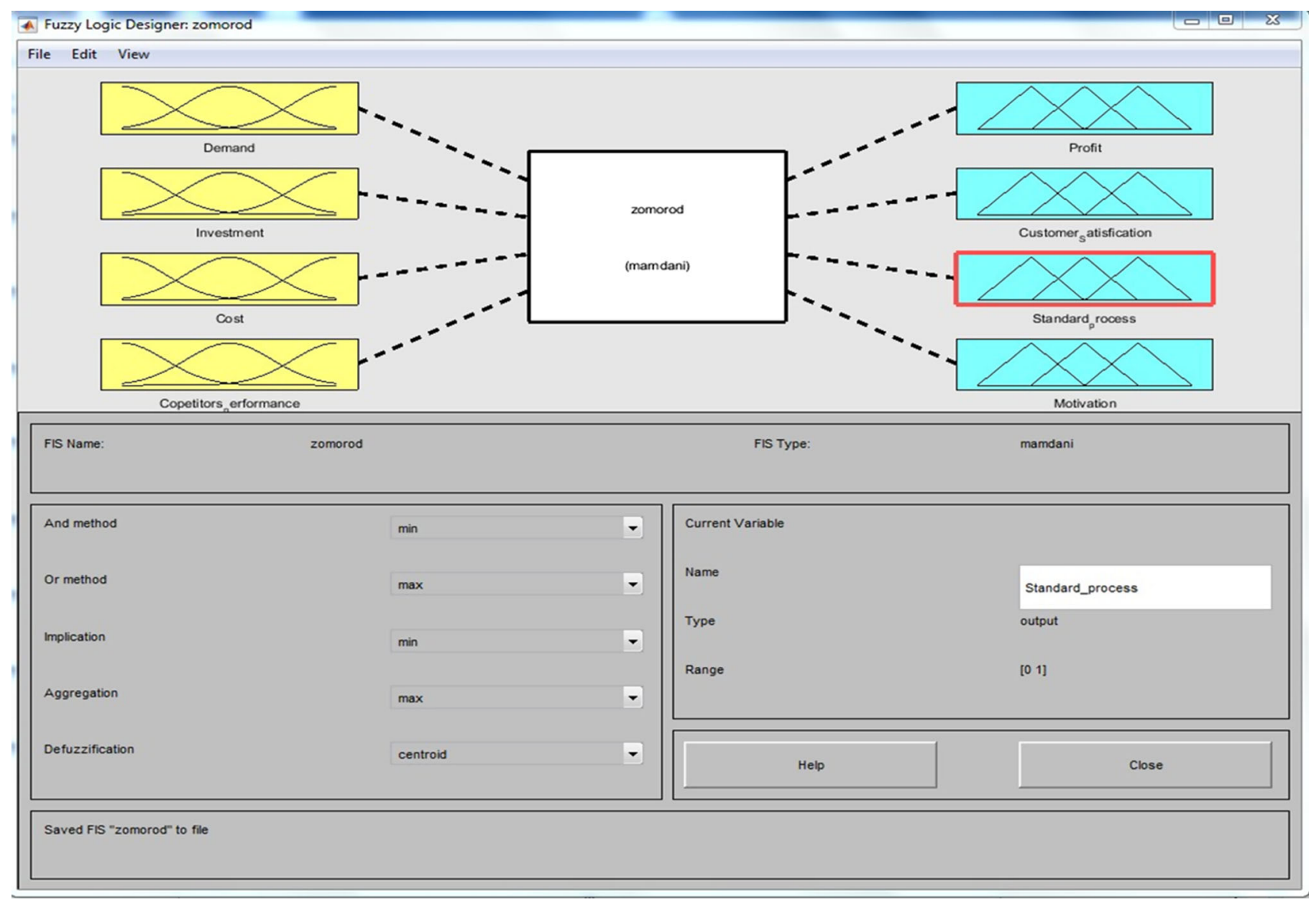

Fig. 2 Outline of inputs and outputs in fuzzy Mamdani operator 


\section{Second scenario: nightmare}

The foreign investments have plummeted to the least possible level; high rate of immigration of specialized forces has made it difficult to access these man forces and increased the costs of human resources. The economic growth has plunged dramatically, and the stock exchange indices have also fallen sharply. There is a sharp decrease in demands because the projects have been stopped.

\section{Third scenario: great wishes}

The desirable political stability and implementing the effective policies on privatization and investment security have attracted foreign investments, and it is possible for the foreign rivals to operate in Iran's market. The economic growth is more than what was set in 20 -year vision plan.

The combinations of stimulus amounts of different scenarios are presented in Table 5.

The main vital success factors in each one of the four aspects are presented in Table 6 .

Since all extracted environmental stimuli do not necessarily affect the performance of a strategy and also the implementation of each strategy does not affect all vital success factors, at first the way environmental stimulus and vital success factors form the relationship with each strategy is to be identified in order to create the knowledge base of each strategy. Then, the impact of a particular strategy on the organization's performance is expressed through changing one of the stimuli while others are maintained the same, and the result is registered in the strategy knowledge base. The knowledge base of four identified strategies is presented in Table 7.

All strategies obtained in the comparison stage have been listed in the first column. A different combination of the stimuli that can potentially occur has been presented in each row, and the results obtained from implementing the strategies in the given conditions have been presented in the vital success factor column. As it can be seen in the table, all stimuli do not necessarily affect a strategy. Finally, the quantitative amounts of each scenario are delivered to the system as the input vector and the amounts of key factors in performance are received as the output. Figure 2 presents an outline of the inputs and outputs in Mamdani fuzzy operator in MATLAB software.

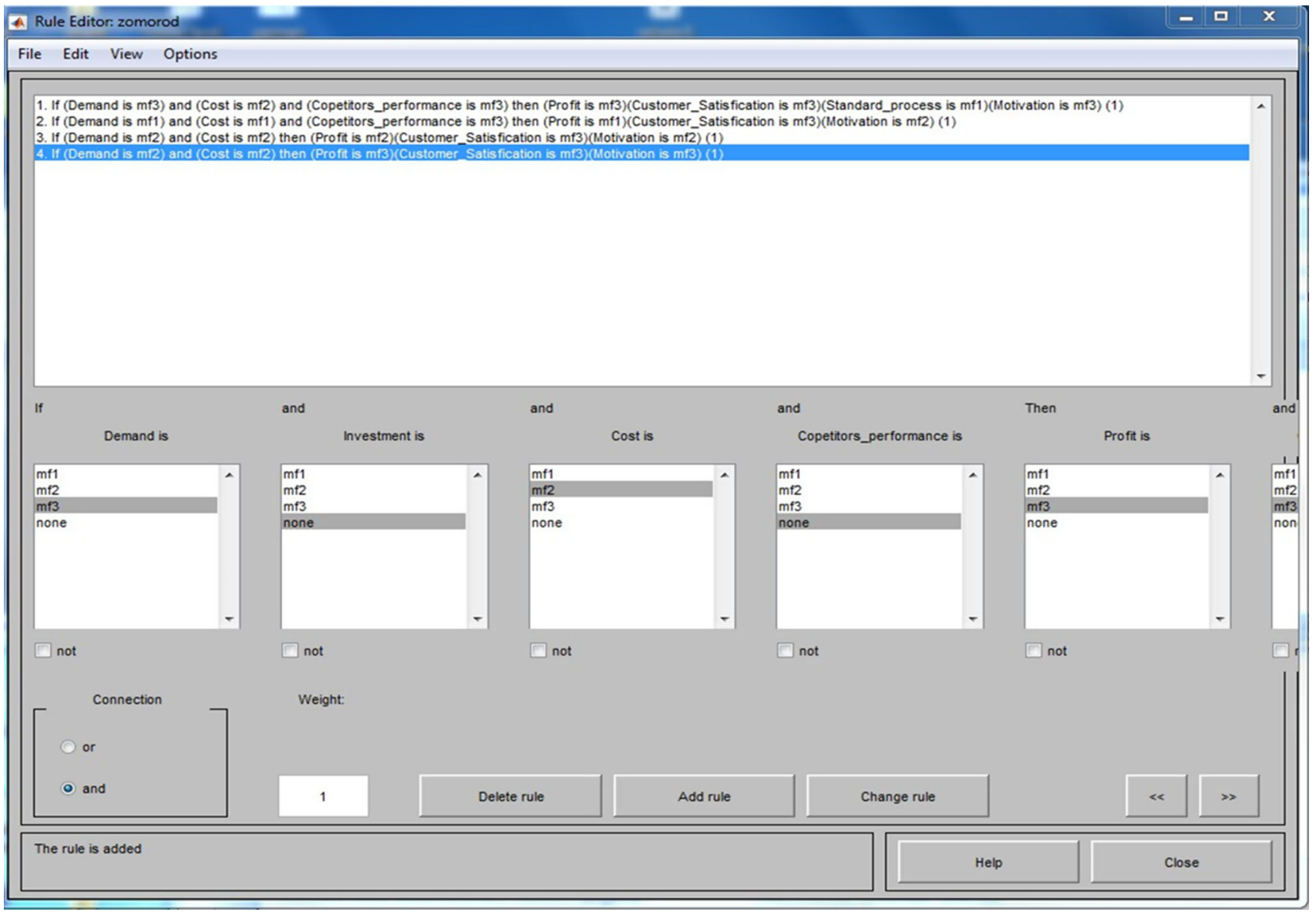

Fig. 3 Cost reduction strategy knowledge base 
In the following, the quantified amounts of the scenarios (Table 5) have been delivered to the system as input vector and the key performance amounts have been received as the output. For example, the input vector of the first scenario (predictable world) that is presented in Table 5 is $(2$, $5,6,5,3,2,5)$. As it can be observed, the results of introducing this vector to the cost reduction strategy knowledge base are $(5,5,6,3,8,1,4,2)$ that shows the organization's key performance amounts in case the cost reduction strategy is implemented in the first scenario. Then, the knowledge base of each one of the four strategies presented in Table 7 is delivered to the system. Figure 3 shows cost reduction strategy knowledge base.

The results obtained from testing other strategies in different scenarios are presented in the following figure.

The degrees of robustness of each strategy in different states are calculated assuming different combinations for the probability of occurrence of a scenario; the results of the calculations are presented in Fig. 4 and Table 8. As it can be seen in the following table, two strategies of cost reduction and partnership have dominated other strategies and they are more attractive.

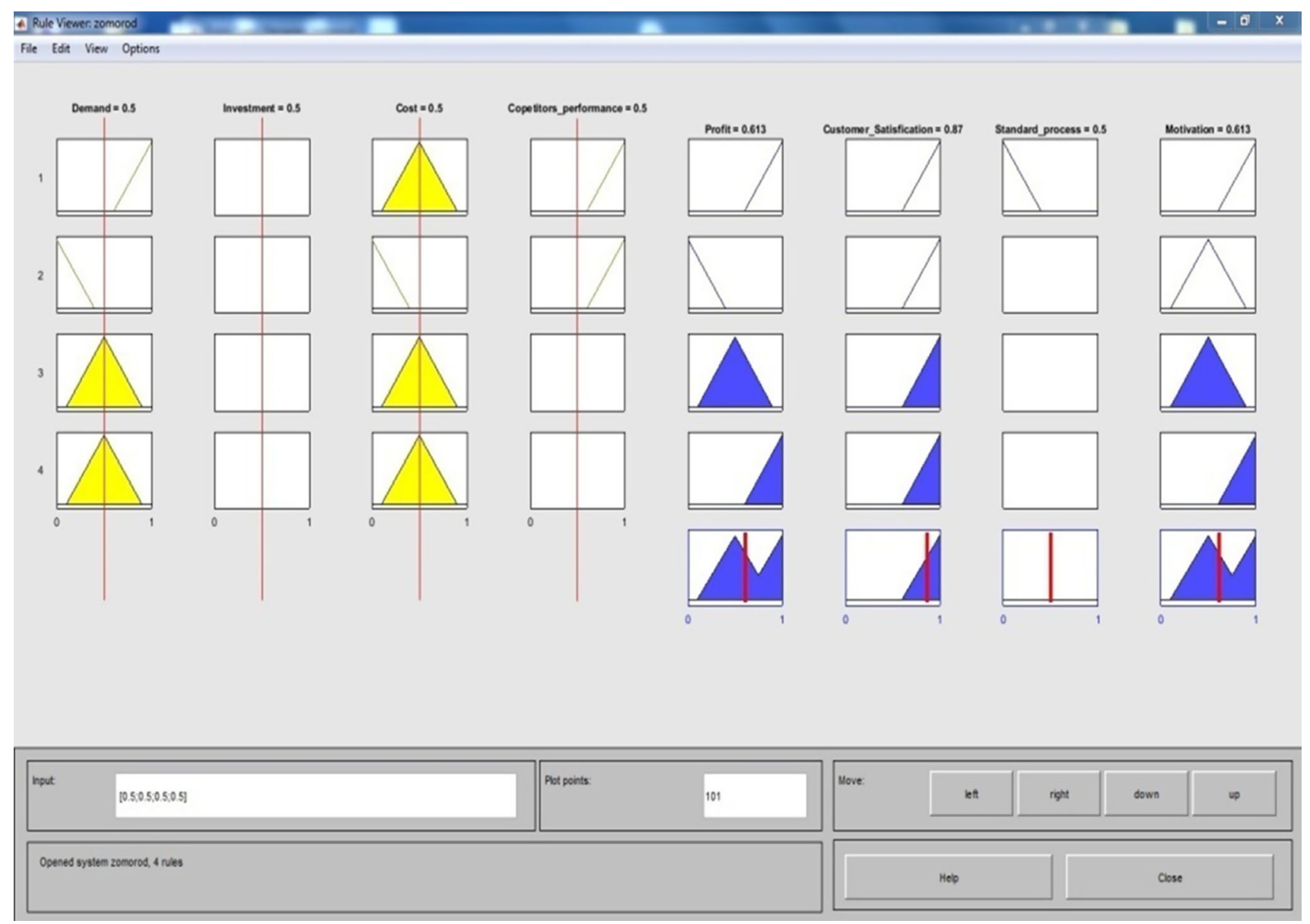

Fig. 4 Sample fuzzy rules for cost reduction strategy

Table 8 Performance of the organization after using strategy in scenarios

\begin{tabular}{lllccc}
\hline Strategy & Scenario & $\begin{array}{l}\text { Strategy 1 } \\
\text { Developing the products }\end{array}$ & $\begin{array}{l}\text { Strategy 2 } \\
\text { Developing the market }\end{array}$ & $\begin{array}{l}\text { Strategy 3 } \\
\text { Reduction in cost }\end{array}$ & $\begin{array}{l}\text { Strategy 4 } \\
\text { Cooperation }\end{array}$ \\
\hline Scenario 1 & Predictable future & 6.5 & 5.5 & 7 & 6.8 \\
Scenario 2 & Nightmare & 4.5 & 5.7 & 7.2 & 6.3 \\
Scenario 3 & Great wishes & 5 & 6.6 & 6.6 & 7.1 \\
Degree of robustness & 25.4 & 27.1 & 25.4 & 25.9 \\
\hline
\end{tabular}


Figure 5 shows the decision levels in the first strategy. As it can be seen in Fig. 5, the changes in output cost will be deeply affected by the amount of input demands.

According to Fig. 5, the partnership strategy will be more appropriate than the cost reduction strategy only in the first, third and fifth states, i.e., the conditions where the third scenario (great wishes) is more probable to occur than two other scenarios. In addition to the above items, as it was mentioned before, the managers of the organization do not pay enough attention to the costs and the studies are conducted by heavy costs and low efficiency. Partnership is possible and profitable when the organization is able to reform the structure of its costs, standardize its processes and enjoy the required efficiency.

With regard to Fig. 6, if the environmental conditions and different trends continue in the same way and as they are expected to continue or even if the conditions become very undesirable or urgent and most of the predictions prove to be wrong and the environmental conditions become worse than what they are now, in both cases, the

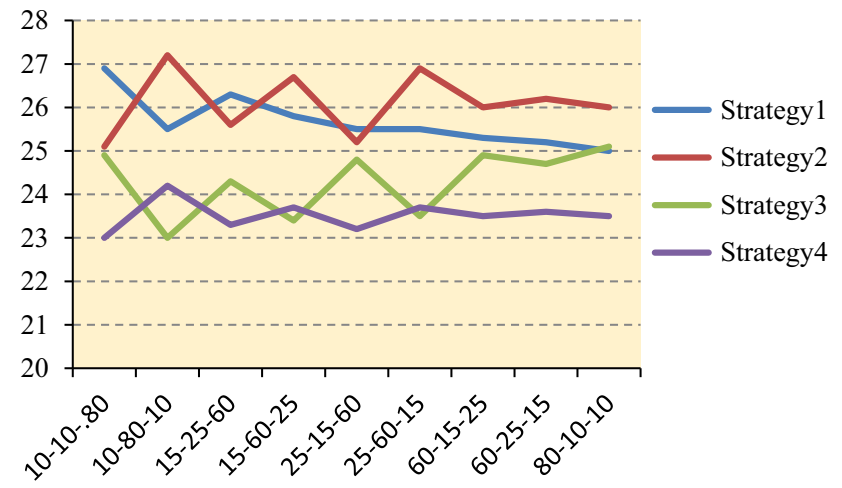

Fig. 6 Combination of occurrence probability of each scenario

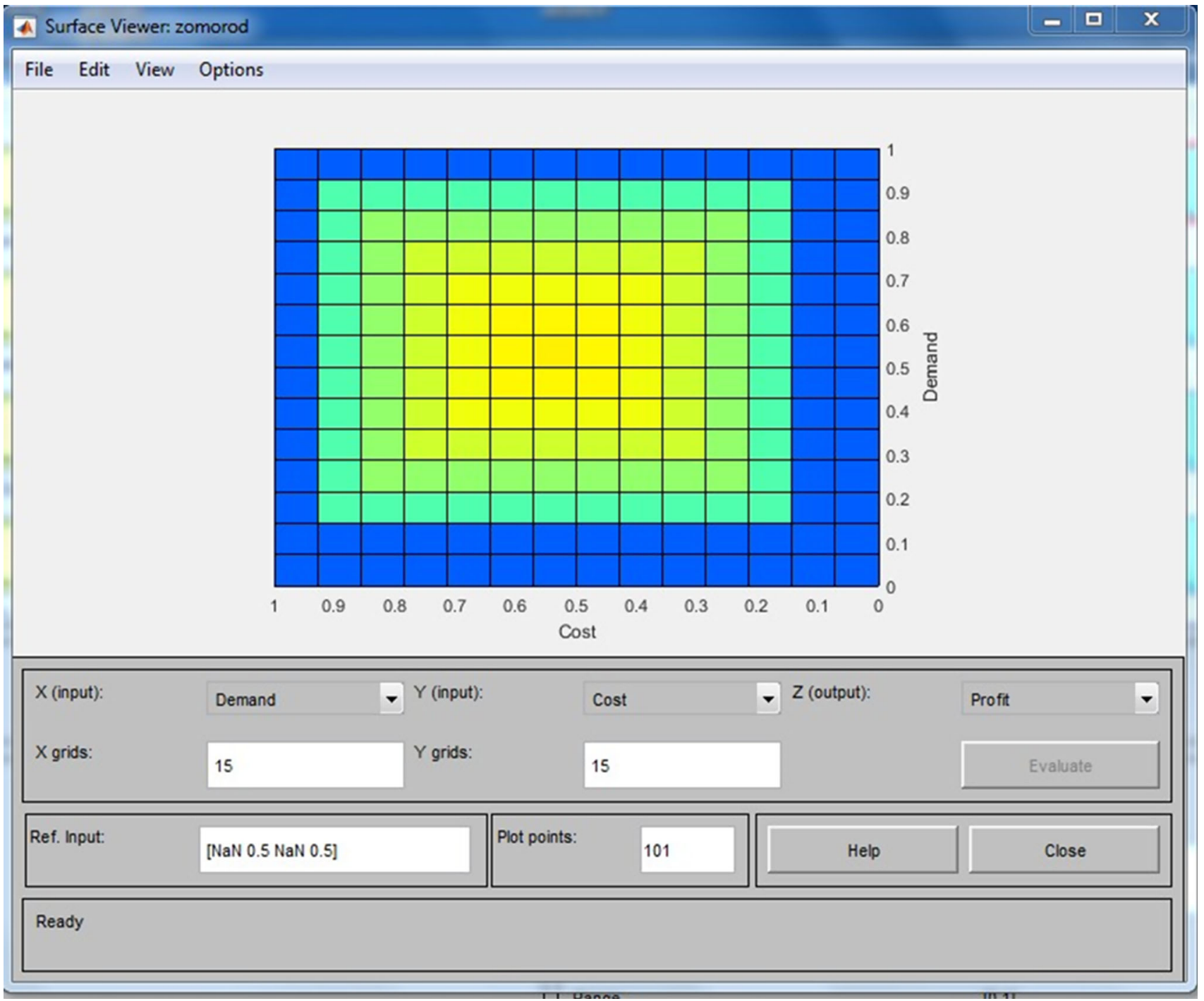

Fig. 5 Decision levels in the first strategy 
cost reduction strategy will be the best strategy of the organization to deal with the environmental conditions. If the environment is desirable for the organization and all variables change much better than the expected amounts, the cost reduction strategy is still an acceptable option for the organization. Therefore, the cost reduction strategy will maintain its robustness and power regardless of what scenario may occur, and it is introduced as a highly reliable strategy. In other cases, i.e., at the time when the scenarios of "predictable future" and "nightmare" are highly probable to occur, the cost reduction strategy is the most appropriate strategy of the organization. Furthermore, if the great wishes scenario occurs, the cost reduction strategy will not lose its acceptability and it will still remain the second best one among the desirable strategies of the organization after the partnership strategy.

\section{Conclusion}

Nowadays, the assumption that the future will be the same as the present is a wrong assumption. Uncertainty is embedded in the very nature of the future, and dealing with it correctly is one of the most difficult tasks assigned to the manager. Uncertainty has a significant effect on the efficiency of the devised strategies. Therefore, the present article examines the uncertainty atmosphere in business. For this purpose, we have expressed the organizations' need for the new planning methods to prepare them in advance for the uncertain factors and environmental changes. A method by the name of robust strategic planning made up of the scenario planning and fuzzy inference system has been proposed to model uncertainty in the field of strategic planning. The results of the research have been examined as a case study for Zomorrod Carpet Company. For this purpose, at first the appropriate strategies have been selected to deal with the uncertainty environment in this company. The reasons to choose these strategies are: technical power and the appropriate infrastructure of the company in comparison with other domestic rivals, cheap specialized man force and the possibility that this market is established outside Iran. The results of this research show that the existence of unfulfilled demands in some parts of the market is among the main factors affecting the mentioned strategy. In the following, the given strategies are ranked using the robust strategic planning approach as follows: 1-cost reduction, 2-partnership, 3-developing the products, 4-developing the market.

Also, we should pay attention to the point that the partnership strategy that requires the investments of the foreign organization in Iran's market is heavily dependent on the economic stability and the Iran's political relations with the advanced countries and it is deeply affected by these factors. As it can be understood from the above reasons, the selected strategy for the quantitative strategic planning matrix method is the best strategy for the organization if the third scenario, i.e., the great wishes, is more likely to occur than the two other scenarios. However, in other cases, i.e., when the first and second scenarios are more likely to occur than the third one, this strategy will no longer be the best choice. Four main strategies were analyzed in this study. More strategies can be investigated for other applications. We have used Mamdani FIS, and other FISs may be used for inference engine. The scenario planning should be implemented for other businesses or using other methods including hybrid methods such as fuzzy neural network, genetic or fuzzy regression. The dynamic of the strategies may be modeled in the future researches through system dynamics.

Open Access This article is distributed under the terms of the Creative Commons Attribution 4.0 International License (http://creative commons.org/licenses/by/4.0/), which permits unrestricted use, distribution, and reproduction in any medium, provided you give appropriate credit to the original author(s) and the source, provide a link to the Creative Commons license, and indicate if changes were made.

\section{References}

Aghazadeh H (2015) Strategic marketing management: achieving superior business performance through intelligent marketing strategy. Procedia Soc Behav Sci 207(20):125-134

Bayar T, Cornett MM, Erhemjamts O, Leverty T, Tehranian H (2018) An examination of the relation between strategic interaction among industry firms and firm performance. J Bank Finance 87:248-263

Brentan BM, Luvizotto E Jr, Herrera M, Izquierdo J, Pérez-García R (2017) Hybrid regression model for near real-time urban water demand forecasting. J Comput Appl Math 309:532-541

Burge SP, Luke M (2017) Business models for distributed energy resources: a review and empirical analysis. Energy Policy 109:230-248

Chen Y, Tan H (2017) Short-term prediction of electric demand in building sector via hybrid support vector regression. Appl Energy 204:1363-1374

Cosenz F, Noto G (2018) A dynamic business modelling approach to design and experiment new business venture strategies. Long Range Plan 51(1):127-140

Dmitrieva D, Ilinova A, Kraslawski A (2017) Strategic management of the potash industry in Russia. Resour Policy 52:81-89

Fjeldstad SD, Snow CC (2018) Business models and organization design. Long Range Plan 51(1):32-39

Gao J, Xie Y, Gu F (2017) A hybrid optimization approach to forecast automobile sales of China. Adv Mech Eng 9(8):17-32

Greiner R, Puig J, Huchery C, Collier N, Garnett ST (2014) Scenario modelling to support industry strategic planning and decision making. Environ Modell Softw 55:120-131

Hu J, Liu H, Chen Y, Qin J (2017) Strategic planning and the stratification of Chinese higher education institutions. Int J Educ Dev. https://doi.org/10.1016/j.ijedudev.2017.03.003 
Jiménez F, Sánchez G, García JM, Sciavicco G, Miralles L (2017) Multi-objective evolutionary feature selection for online sales forecasting. Neurocomputing 234(19):75-92

Karimi N, Moghimbeigi A, Motamedzade M, Roshanaei G (2016) Evaluation of related risk factors in number of musculoskeletal disorders among carpet weavers in Iran. Saf Health Work 7(4):322-325

Kuo RJ, Tseng YS, Chen Z-Y (2016) Integration of fuzzy neural network and artificial immune system-based back-propagation neural network for sales forecasting using qualitative and quantitative data. J Intell Manuf 27(6):1191-1207

Lessmann S, Voß S (2017) Car resale price forecasting: the impact of regression method, private information, and heterogeneity on forecast accuracy. Int J Forecast 33(4):864-877

Light I, Shahlapour P (2017) Transnational Iranian entrepreneurs in the import/export industry of Los Angeles. In: Rezaei S, Dana L-P, Ramadani V (eds) Iranian entrepreneurship, pp 195-205

Mamdani EH, Assilian S (1975) An experiment in linguistic synthesis with a fuzzy logic controller. Int J Man Mach Stud 7(1):1-13

Martinsons MG, Davison RM, Huang Q (2017) Strategic knowledge management failures in small professional service firms in China. Int J Inf Manage 37(4):327-338
Norooz S, Wikner J (2017) Sales and operations planning in the process industry: a literature review. Int $\mathrm{J}$ Prod Econ 188:139-155

Papke-Shields KE, Boyer-Wright KM (2017) Strategic planning characteristics applied to project management. Int J Proj Manag 35(2):169-179

Pesonen P (2009) Innovation and dynamic strategy: planning and implementing continuous renewal. In: Saarinen J, Rilla N (eds) Changes in innovation. Palgrave Macmillan, London, pp 93-114

Propa G, Banwet DK, Goswami KK (2018) Performance measurement and management of handmade carpet industry. In: Goswami KK (ed) Advances in carpet manufacture, a volume in the textile institute book series, 2nd edn, pp 485-527

Sagaert YR, Aghezzafa E-H, Kourentzes N, Desmet B (2018) Tactical sales forecasting using a very large set of macroeconomic indicators. Eur J Oper Res 264(2):558-569

Wang F-K, Chang K-K, Tzeng C-W (2011) Using adaptive networkbased fuzzy inference system to forecast automobile sales. Expert Syst Appl 38(8):10587-10593

Zhao S, Zhu Q (2018) A risk-averse marketing strategy and its effect on coordination activities in a remanufacturing supply chain under market fluctuation. J Clean Prod 171(10):1290-1299 